\title{
III.
}

\section{Über umschriebene bindegewebige Verdickungen an der inneren Fläche der Dura mater bei Pachymeningitis hae- morrhagica interna.}

\author{
Von
}

\author{
Dr. G o n z a lo R. La f o r a, Madrid, \\ Histopathologe am "Government Hospital for the Insane" in. Washington, D. C.
}

(Hierzu 2 Textfiguren.)

Wir wollen hier über gewisse nabelartige Verdickungen der inneren Fläche der Dura berichten, die wir bei drei Fällen von beginnender hämorrhagischer Pachymeningitis beobachtet haben. So viel wir wissen, sind die in Frage kommenden Gebilde nur einmal vorher beschrieben worden. Die einzige Arbeit, in welcher Gebilde, wie wir sie beschreiben werden, erwähnt sind, wurde 1895 von Middlemass und Robertson veröffentlicht. Robertson betonte,

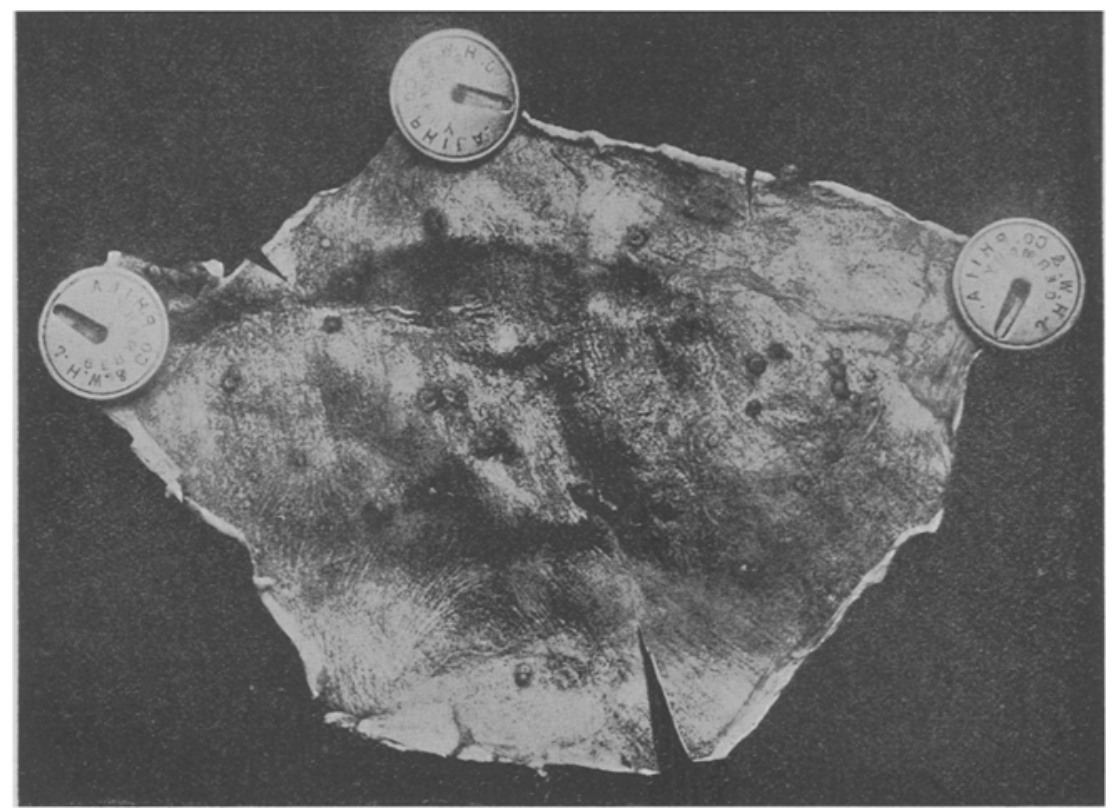

Fig. 1. Innere Oberfläche der Dura mater mit Pachymeningitis haemorrhagica interna, die zahlreiche nabelartige bindegewebige Herde zeigt.

daß diese Herde ,etwas selten auftreten, doch wenn die Membran gut durehlichtet wird, leicht als dunkle, undurchsichtige, ein wenig nabelartige Flecke mit bloßem Auge zu erkennen sind". Als vorausgehende Prozesse beschrieb er andere nur mikroskopisch sichtbare Gebilde, die etwas öfter gefunden werden. Dieses 
sind kleine unregelmäBige Flecken mit einem undurchsichtigen und etwas granuliertem Aussehen, die über die ganze Oberfläche zerstreut erseheinen (horizontale Schnitte). Sie wurden gewöhnlich inmitten der intervaskulären Areale beobachtet, eine Tatsache, die ihn bewog, ihre Entstehung einer ungenügenden Blutzufuhr zuzuschreiben. Er sagt, daß diese granulierten Flecke (nicht aber die knötchenförmigen Verdickungen) sehr oft in der Dura von Geisteskranken und älteren Patienten gefunden werden.

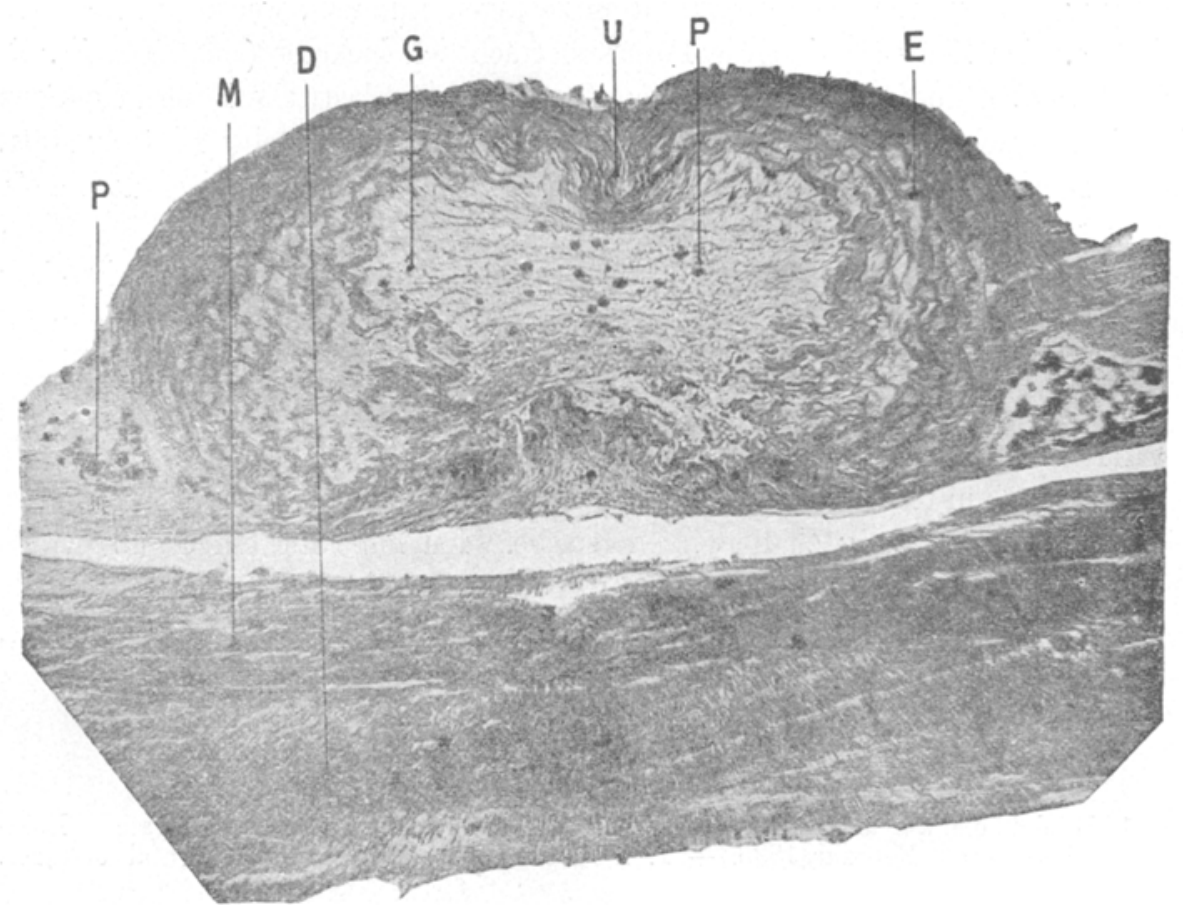

Fig. 2. Mikrophotographie des Querschnittes eines bindegewebigen Herdes der Dura mater (mit Alzheimer-Mann scher Methode gefärbt). C. Lockeres Bindegewebe des Zentrums des Herdes. D. Dura mater. E. Bindegewebsfasern mit Zickzack-Verlauf, welche die Kapsel des Herdes bilden. M. Haemorrhagișche Pseudomembran. P. Pigmentbeladene Zellen im Zentrum und in der Umgebung des Herdes. U. Nabelartige Depression des Herdes, in de $m$ die Bindegewebsfasern sich einwärts gegen das Zentrum des Herdes beugen.

Die makroskopisch sichtbaren Verdickungen, die wir hier beschreiben wollen, werden sehr selten gefunden, und zwar immer nur in Zusammenhang mit hämorrhagiseher Pachymeningitis, eine Tatsache, die nicht von $R$ oberts on konstatiert ist und welche die Entstehung dieser Herde aus jenen anderen Gebilden, die so häufig in der Dura gefunden werden, sehr unwahrscheinlich macht. Diese Herde sind runde oder ovale Gebilde von 1 bis $2,5 \mathrm{~mm}$ im Durchmesser und mit einer deutlichen nabelartigen Depression im Zentrum der Verdickung. Sowohl diese Depression wie anch die äußeren Ränder der Herde zeigen eine sehr dunkle 
Farbe, was von der Ansammlung blutpigmentbeladener Zellen herrührt. Die Herde können manchmal in Gruppen von drei und mehr erscheinen, aber zwei zusammen oder nur vereinzelte sind häufiger zu finden (siehe Textfig. 1). Der Ring oder Hof des Herdes zeigt oft eine weiße Farbe. Das ist jedoch nicht immer so, indem diejenigen Herde, die inmitten stark hämorrhagiseher Gebiete liegen, häufig eine gleichmäßig dunkle Farbe zeigen.

Histopathologisch: die Herde haben eine bindegewebige Struktur. Die Bindegewebsfasern umgeben die Herde in zackigen Bündeln; welche im Zickzack verlaufen. Im Zentrum sind die Fasern beträchtlich lockerer (siehe Textfig. 2), und oft werden dort einige Pigmentzellen gefunden. Elastische Fasern kommen nicht in Betracht. Sehr häufig findet im Zentrum des Herdes eine Blutung statt. die den zentralen Teil des lockeren Bindegewebes erfüllt. In den Seiten der Herde werden häufig kleine Ansammlungen von Pigmentzellen gefunden.

Die Bedeutung dieser Herde und ihre Entstehungsweise ist noch im Dunkel; ihre vaskuläre Entstehrung scheint mir unwahrscheinlich, ich glaube vielmehr, daß sie durch einen reaktiven Prozeß des Bindegewebes gegen die kapillaren Blutergüsse hervorgerufen werden. Die Blutungen werden später resorbiert und lassen die Pigmentzellen oder Körnchenzellen mit Blutpigment zurück. Die Herde liegen immer inmitten der organisierten pachymeningitischen Gewebe und haben keine direkte Beziehung zu dẹm Duragewebe. Ich habe nie ein Gefäß in den Herden finden können, was zugunsten einer ungenügenden Ernährung der Herde spricht. Sehr wahrseheinlich sind diese Herde nur vorübergehende Gebilde, welche wieder resorbiert werden, nachdem ihre reaktive Funktion erfüllt ist.

Literatur.

1. Middlem a B und R obertson: Morbid conditions of the dura mater. Edinburgh Med. Journal, Februar 1895. - 2. R o b erts o n: Pathology of mental diseases. Edinburgh, 1900, W. F. Clay, p. 101.

\section{IV. \\ ïher eine Fortsatzbildung am vorderen Rande des Chiasma nervorum opticorum.}

(Aus dem Pathologischen Institute zu Straßburg i. E.)

$$
\begin{aligned}
& \text { Von } \\
& \text { Dr. Sagi i O gat a } \\
& \text { aus Japan. } \\
& \text { (Hierzu } 6 \text { Textfiguren.) }
\end{aligned}
$$

Diese eigentümliche Fortsatzbildung wird sehr selten erwähnt. In der mir zugänglichen Literatur fand ich nur zwei derartige Fälle. 